\title{
Rehabilitation Of Stroke Aphasia: Topics Of Research
}

\section{Fariba Yadegari}

PhD of speech therapy, Associate Professor of Speech Therapy Department, University of Social Welfare and Rehabilitation Sciences, Tehran, Iran.

*Corresponding Author: Email: fa.yadegari@uswr.ac.ir

Background: Stroke may result in aphasia, an acquired language disorder which affects receptive and expressive language. The symptoms are observed in the auditory-verbal processing, oral expression, written expression and written language processing. As spoken language is the strongest tool of human communication, loss of it may cause great destructive consequences in the social and personal life of the affected individual. People with aphasia (PWA) and their carers seek rehabilitation in an effort to remove or reduce the effects. Speech-language pathologists (SLPs) are professional in offering such service. This paper aims at addressing new approaches and current research questions about the factors affecting the therapy.

Main points: The issues which aphasia therapy research and reviews have addressed are the ones that are asked frequently in clinical settings and research areas. These include the intensity of treatment, the best post-onset time to start, quality of individualized treatment, efficacy of newly-introduced interventions, and the interventions based on the International Classification of Functioning, Disability and Health (ICF) model with emphasis on activity/participation.

Findings: The results of studies have revealed that compact therapy in a short period of time might result in better recovery of aphasia. Studies also indicated that starting treatments very early with intensive programs leads to the best therapy results. Chronic stage is good for some intervention strategies as well; however, the effectiveness of these interventions requires further investigations. Moreover, better treatment results could be attained by tailoring the program to match with individual needs. Manipulation of word frequency, personal relevance, and considering reaction time are among important factors in tailor-made therapies. Besides, the conceptual model of ICF which incorporates impairment (body structure and function), activity and participation in the assessment and treatment of aphasia are being researched currently. This model provides a comprehensive functional communicative lookout of the patient.

Conclusion: There is no prescribed intervention for different types of aphasia. Customized therapeutic programs which are tailored to the unique needs of the patients and incorporate primary impairment, functional limitations and social restrictions of the patient are needed. This therapy should be intensive enough and be administered as early as possible.

Key words: aphasia, therapy, stroke

DOI: 10.7575/aiac.abcmed.ca1.38

A I Published Date: February 2017

Peer-review is under responsibility of the 9th Iranian Stroke Congress.

Published by Australian International Academic Centre, Australia

This published work is open access under the CC BY license.

Available online at www.abcmed.aiac.org.au 